\title{
Responding to Typhoon Haiyan in the Philippines
}

\author{
Michelle McPherson, ${ }^{a}$ Megan Counahan ${ }^{b}$ and Julie Lyn Hallb
}

Correspondence to WPSAR@wpro.who.int.

$\mathrm{T}$ he Philippines is a disaster-prone country, ${ }^{1}$ ranked as the second highest country worldwide at risk of natural disasters. ${ }^{2}$ On 8 November 2013, Typhoon Haiyan (local name "Yolanda") made landfall in the Philippines and had significant impact (Box 1). ${ }^{3}$ It was the strongest typhoon to have ever made landfall in the western North Pacific Ocean with a storm surge of 5-6 metres. ${ }^{4}$ Typhoon Haiyan left a corridor of destruction across the Philippines (Figure 1) and affected the lives of 16 million people, devastated a health system and challenged every sector of the country. ${ }^{3}$ Regions 6,7 and 8 - Western, Central and Eastern Visayas - were the most affected (Figure 1).

As a result of Typhoon Haiyan, a national state of calamity was declared by the President of the Philippines on 11 November 2013, and the Inter-Agency Standing Committee rated it as a Level 3 emergency. ${ }^{5}$ For the first time, the World Health Organization (WHO) graded an event as a Level-3 emergency according to their Emergency Response Framework. ${ }^{6}$ The resulting response was immense, and involved both national and international support. The Health Cluster was coled by the Philippines Department of Health (DOH) and the WHO Representative Office in the Philippines. Key efforts of the Health Cluster included: ${ }^{7}$

- coordination of over 150 foreign medical teams that conducted approximately 20000 consultations and more than 5000 surgeries;

- delivery of over 500 tonnes of medical equipment and supplies;

- training of health care workers in key areas 300 in disease surveillance, 300 in maternal and child health (90 on Essential Intrapartum Newborn Care and 206 on Kangaroo Mother Care), 330 in mental health (200 community

\section{Box 1. Impact of Typhoon Haiyan in the Philippines ${ }^{3}$}

- Around 3.4 million families (16 million individuals) were affected across $12 \quad 139$ villages/communities in 44 provinces, 591 municipalities and 57 cities across Regions 4A, 4B, 5, 6, 7, 8, 10, 11 and Caraga.

- There were 6293 individuals reported dead, 28689 injured and 1061 still missing.

- A reported 890895 families (4 million individuals) were displaced. Of these 21000 families (100 000 individuals) were served inside evacuation centres.

- There were 1.1 million damaged houses of which 551000 were totally damaged, and the rest were partially damaged.

- The total cost of damages has been estimated at US\$ 864 million with US\$ 435 million for infrastructure and US\$ 440 million for agriculture in affected regions.

- There were 600 health facilities damaged.

- In Tacloban City, the capital of Leyte province, more than $1600 \mathrm{~m}^{2}$ of debris and garbage have been cleared.

workers in psychosocial first aid and 130 health professionals in the Mental Health Gap Action Programme), 340 in water quality and 215 in waste management;

- a vaccination campaign across affected the areas conducted in November 2013 vaccinated 108783 children against measles and 49902 for poliovirus; and

- replacing the equipment to restart the rabies vaccination campaign across the Eastern Visayas region, including over 60000 dog vaccines and 5000 vaccine carriers.

\footnotetext{
Western Pacific Surveillance and Response Journal, Division of Health Security and Emergencies, World Health Organization Regional Office for the Western Pacific, Manila, Philippines.

Office of the WHO Representative in the Philipines, Sta Cruz, Manila, Philippines.

Published: 6 November 2015

doi: 10.5365/wpsar.2015.6.4.HYN_026
} 
Figure 1. Pathway of Typhoon Haiyan and the percentage of affected population by municipality, the Philippines, 12 November $2013^{3}$
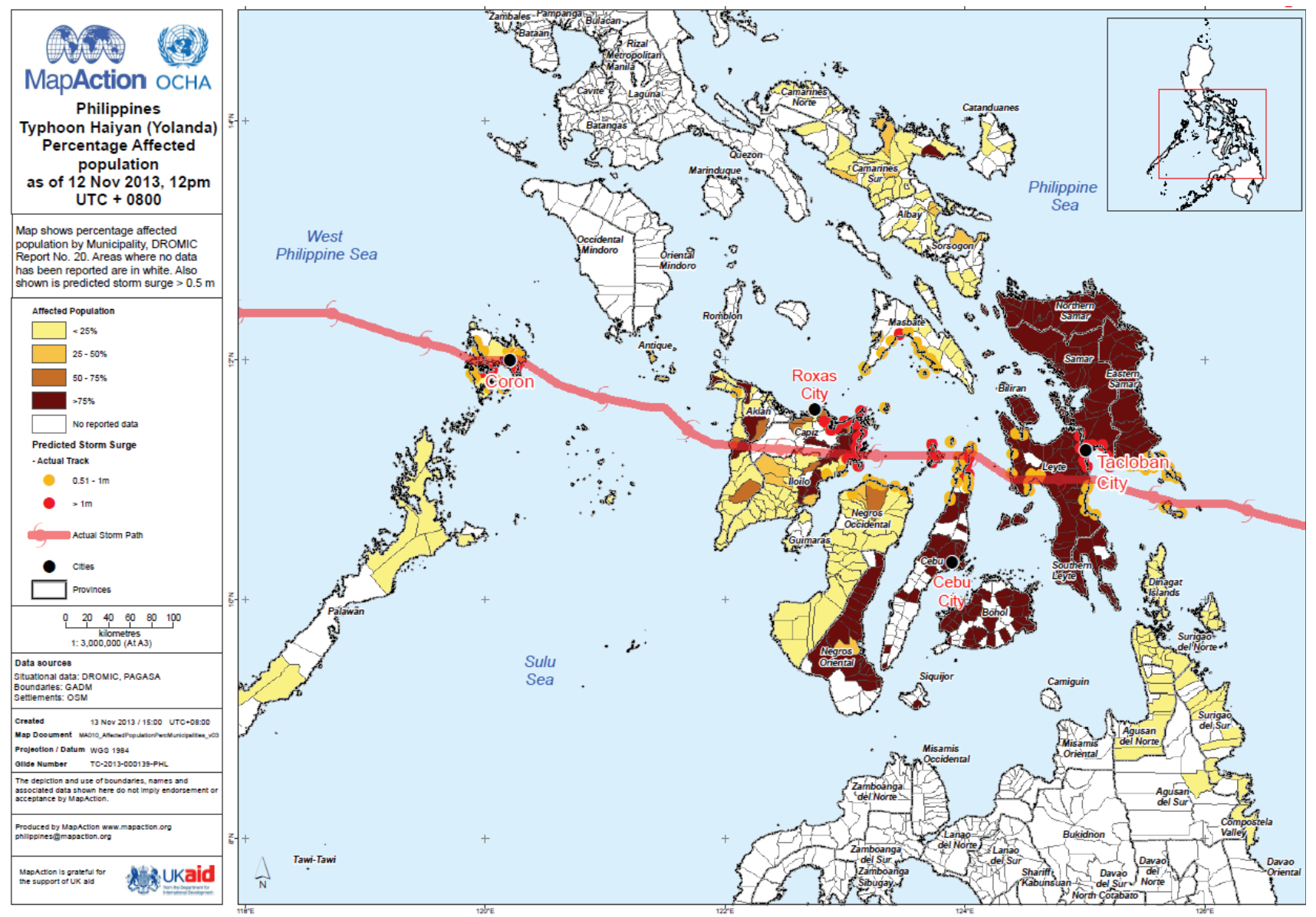

In this issue of the Western Pacific Surveillance and Response Journal (WPSAR), we provide a summary of the health response to Haiyan through 20 articles. As described in the brief report by Gocotano et al., ${ }^{8}$ 18 months after Haiyan, the WHO Representative Office in the Philippines and the DOH wanted to document the lessons learned from Haiyan. WPSAR was pleased to be involved with this project, as it matched with the aim of building capacity in communicating epidemiological and operational research within the WHO Western Pacific Region. It will hopefully contribute to reversing the trend of authors from outside disaster-affected countries publishing manuscripts about events. ${ }^{8}$

This Typhoon Haiyan issue starts with a perspective article about the transition period from response to recovery; it argues that the transition period for Haiyan occurred from three to seven months post-Haiyan and was an overlap of different activities among health sector responders. ${ }^{5}$
Following Haiyan, many existing health programmes in the Philippines required rebuilding, and in some cases, they were improved. The tuberculosis programme had to locate and facilitate treatment for existing patients and restore diagnostic capabilities; this was accomplished within two months. ${ }^{9}$ New guidelines for maternal and newborn care following emergencies and disasters were developed and used extensively, including implementing Kangaroo Mother Care in 15 health facilities. ${ }^{10}$ Increased coordination of services for people with disability improved beyond pre-Haiyan levels, demonstrating that it is possible to "build back better" after the response to a disaster. ${ }^{11}$ Health system recovery for noncommunicable diseases (NCDs) in Region 8 was based on the WHO Package of Essential Noncommunicable Disease Interventions and resulted in trained health service providers; availability of essential equipment, supplies and medicines; functional referral systems; and use of monitoring tools. ${ }^{12}$ 
Several new initiatives were implemented during the response to Haiyan. Social media was used by WHO for the first time in the Philippines and was a key part of the risk communication strategy. ${ }^{13}$ Another first was the classification and registration form used for foreign medical teams which proved beneficial for coordination. ${ }^{14}$ A community-based alcohol intervention programme was piloted in Tacloban City and showed there was a problem with alcohol and introducing a programme to address it possible with minimal resources. ${ }^{15}$

There were three disease surveillance systems used during the response to Haiyan: Philippine Integrated Disease Surveillance and Response (PIDSR), Event-based Surveillance and Response (ESR) and Surveillance in Post Extreme Emergencies and Disasters (SPEED). An assessment of when these systems were operational showed that the two routine systems (PIDSR and ESR) were disrupted only in Leyte province (Region 8), yet almost all areas delayed the activation of SPEED. ${ }^{16}$ Another assessment, conducted 16 months after Haiyan in Region 8 only, showed that the reestablishment of PIDSR was slow and not operating at pre-Haiyan levels. ${ }^{17} \mathrm{~A}$ third study analysed the data from SPEED for the three noncommunicable syndromes and found high blood pressure, acute asthma attacks and diabetes were of concern following Haiyan. This study also recommended a more comprehensive surveillance system for NCDs for future disaster response. ${ }^{18}$

Also in this issue, several field investigation reports provide a snapshot of different components of the health response to Haiyan. An assessment of evacuation centres conducted two weeks after Haiyan suggested a variation in the size of the evacuation centres and mixed levels of services. ${ }^{19}$ A team from $\mathrm{DOH}$ was involved in the management of the dead, which was challenging due to limited access to the affected areas. ${ }^{20}$ Water quality testing conducted in the early stages of the response was repeated after local governmental unit teams were trained in water testing, sanitary surveys, water treatment and water safety planning. ${ }^{21}$ Efforts for dengue prevention and control were multifaceted, and despite a multitude of potential breeding sites, there were no outbreaks reported. ${ }^{22}$ The work of the administrative team from the WHO Representative Office in the Philippines was unprecedented; they processed 22 times the annual budget, more than 100 international consultants were hired and the staff more than doubled..$^{23}$
The response to Haiyan provided other key lessons for future responses. A case control study showed that not evacuating before the storm, despite official recommendations, was the greatest risk factor for dying during Typhoon Haiyan and that the use of the term "storm surge" to warn the public before Typhoon Haiyan was not understood. ${ }^{24}$ Medicine management during the response was difficult and was compounded by receiving donation of short-dated, near-expiry and unnecessary items which created additional burden on the health system. ${ }^{25} \mathrm{~A}$ small study of self-reported health costs suggested many people had catastrophic out-of-pocket health expenditures with consultation and transportation costs as the main barriers to health service utilization. ${ }^{26}$

This cross-section of articles provides many observations and lessons learnt from the health response to Typhoon Haiyan in the Philippines. We would like to highlight what we see as the three key lessons from the overall response. First, there were waves of health needs post-Haiyan, with risks for some communicable diseases (e.g. rabies, dengue and measles) extending through the recovery period and demands for NCDs, mental health and maternal health continuing for months after the official response period had ended. The second lesson was that data to support epidemiological and operational research during disaster response, although required, was often limited and improving essential data collection as part of disaster preparedness would help ensure critical operational research during disaster responses can be undertaken. Finally, we learnt national responders have a wealth of knowledge and experience that needs to be published. Support should be provided for capacity building to facilitate research and the publication of findings to help strengthen the collective response to emergencies.

We are grateful that we have had the opportunity to be part of capacity building of many first time authors in this issue of WPSAR. We would like to thank all the authors for their commitment and perseverance in getting their work published. We also encourage other first time authors to submit their experiences in responding to disasters to WPSAR.

\section{References}

1. Guha-Sapir D, Hoyois PH, Below R. Annual disaster statistical review 2013: the numbers and trends. Brussels, Centre for Research on the Epidemiology of Disasters (CRED), 2014 
(http://www.cred.be/sites/default/files/ADSR 2013.pdf, accessed 9 October 2015).

2. The 2014 World Risk Report. Bonn, United Nations UniversityInstitute for Environment and Human Security (UNU-EHS), 2014 (http://i.unu.edu/media/ehs.unu.edu/news/4070/11895.pdf, accessed 13 October 2015).

3. SitRep No. 108 re Effects of Typhoon Yolanda (Haiyan). Quezon City, National Disaster Risk Reduction and Management Council, 2014 (http://www.Effects_of_Typhoon YOLANDA_(HAIYAN)_SitRep_No_108_03APR $2014 . p d \bar{f}$, accessed 13 October 2015).

4. Mori $\mathrm{N}$ et al. Local amplification of storm surge by Super Typhoon Haiyan in Leyte Gulf. Geophysical Research Letters, 2014, 41:5106-5113. doi:10.1002/2014GL060689 pmid:25821268

5. Gocotano et al. Is the response over? The transition from response to recovery in the health sector post-Haiyan. Western Pacific Surveillance and Response Journal, 2015, 6(Suppl 1):5-9. doi:10.5365/wpsar.2015.6.2.HYN_007

6. Emergency response framework (ERF). Geneva, World Health Organization, 2013 (http://www.who.int/hac/about/erf_.pdf, accessed 9 October 2015).

7. Typhoon Haiyan (Yolanda) one year on: Factsheet overview. Manila, World Health Organization in the Philippines, 2014 (http://www.wpro.who.int/entity/philippines/mediacentre/features/ yolandafactsheetoverview.pdf, accessed 13 October 2015).

8. Gocotano et al. Can you help me write my story? The institutional affiliation of authors of international journal articles on postdisaster health response. Western Pacific Surveillance and Response Journal, 2015, 6(Suppl 1):10-14. doi:10.5365/ wpsar. 2015.6.3.HYN_019

9. Lew et al. Restarting the tuberculosis programme post-Haiyan. Western Pacific Surveillance and Response Journal, 2015, 6(Suppl 1):91-95. doi:10.5365/wpsar.2015.6.2.HYN_009

10. Kitong J, Calibo A. Guidelines and training for maternal and newborn care post-Haiyan. Western Pacific Surveillance and Response Journal, 2015, 6(Suppl 1):15-17. doi: 10.5365/wpsar.2015.6.3.HYN_025

11. Benigno MR et al. Responding to the health and rehabilitation needs of people with disabilities post-Haiyan. Western Pacific Surveillance and Response Journal, 2015, 6(Suppl 1):53-59. doi:10.5365/wpsar.2015.6.2.HYN_010

12. Martinez R et al. Use of the WHO package of essential noncommunicable disease intervention after Typhoon Haiyan. Western Pacific Surveillance and Response Journal, 2015, 6(Suppl 1):18-20. doi:10.5365/wpsar.2015.6.3.HYN_024

13. Cool CT et al. Social media as risk communication tool following Typhoon Haiyan. Western Pacific Surveillance and Response Journal, 2015, 6(Suppl 1):86-90. doi: 10.5365/wpsar.2015.6.2.HYN_013

14. Peiris $\mathrm{S}$ et al. Is registration of foreign medical teams needed for disaster response? Findings from the response to Typhoon Haiyan.
Western Pacific Surveillance and Response Journal, 2015, 6(Suppl 1):29-33. doi:10.5365/wpsar.2015.6.2.HYN_014

15. Czaicki AE et al. Is my drinking a problem? A community-based alcohol intervention programme post-Haiyan in Tacloban City. Western Pacific Surveillance and Response Journal, 2015, 6(Suppl 1):96-101. doi:10.5365/wpsar.2015.6.2.HYN_016

16. Tante $S$ et al. Which surveillance systems were operational after Typhoon Haiyan? Western Pacific Surveillance and Response Journal, 2015, 6(Suppl 1):66-70. doi:10.5365/ wpsar.2015.6.2.HYN_015

17. Gallardo FDL et al. An assessment of the case notification system 16 months after Typhoon Haiyan in Region 8, the Philippines. Western Pacific Surveillance and Response Journal, 2015, 6(Suppl 1):71-75. doi:10.5365/wpsar.2015.6.2.HYN_002

18. Martinez $\mathrm{R}$ et al. Surveillance for and issues relating to noncommunicable diseases post-Haiyan in Region 8. Western Pacific Surveillance and Response Journal, 2015, 6(Suppl 1):21-24. doi:10.5365/wpsar.2015.6.3.HYN_020

19. Ramos AR et al. Rapid health assessments of evacuation centres in areas affected by Typhoon Haiyan. Western Pacific Surveillance and Response Journal, 2015, 6(Suppl 1):39-43. doi:10.5365/ wpsar.2015.6.2.HYN_003

20. Ballera JE et al. Management of the dead in Tacloban City after Typhoon Haiyan. Western Pacific Surveillance and Response Journal, 2015, 6(Suppl 1):44-47. doi:10.5365/wpsar.2015. 6.2.HYN_004

21. Magtibay B et al. An assessment of drinking-water quality post-Haiyan. Western Pacific Surveillance and Response Journal, 2015, 6(Suppl 1):48-52. doi:10.5365/ wpsar.2015.6.2.HYN_011

22. Aumentado $\mathrm{C}$ et al. The prevention and control of dengue after Typhoon Haiyan. Western Pacific Surveillance and Response Journal, 2015, 6(Suppl 1):60-65. doi:10.5365/wpsar.2015.6.3. HYN_018

23. Urquico $\mathrm{R}$ et al. Managing surge staff and resources at the WHO Representative Office in the Philippines during the Typhoon Haiyan response. Western Pacific Surveillance and Response Journal, 2015, 6(Suppl 1):25-28. doi:10.5365/ wpsar.2015.6.3.HYN_023

24. Ching PK et al. An assessment of disaster-related mortality post-Haiyan in Tacloban City. Western Pacific Surveillance and Response Journal, 2015, 6(Suppl 1):34-38. doi:10.5365/ wpsar.2015.6.2.HYN_005

25. Salenga $\mathrm{R}$ et al. Medicines management in the Philippine public sector during the response to Haiyan. Western Pacific Surveillance and Response Journal, 2015, 6(Suppl 1):82-85. doi:10.5365/ wpsar.2015.6.2.HYN_012

26. Espallardo NL et al. A snapshot of catastrophic post-disaster health expenses after Typhoon Haiyan. Western Pacific Surveillance and Response Journal, 2015, 6(Suppl 1):76-81. doi:10.5365/ wpsar.2015.6.2.HYN_017 